\title{
RCD) As ondas da Comunicação Comunitária no
Brasil a partir da análise da Rede Mocoronga de
Comunicação Popular
}

The insights of Community Communication in Brazil from the analysis of the Rede Mocoronga de Comunicação Popular

\section{Marcella Rodrigues Tovar da Silva Carla Baiense Félix ${ }^{2}$}

\begin{abstract}
Resumo: A Comunicação Comunitária trata-se de um processo de luta popular não só por espaços de fala, mas por transformação social e influência política. Tendo em vista os avanços tecnológicos e a apropriação popular dos aparelhos de telefone móveis, a reflexão sobre as novas maneiras de comunicar faz-se necessária. Este artigo tem como objeto de pesquisa a autorrepresentação audiovisual tensionada pela atuação da Rede Mocoronga de Comunicação Popular. Parte-se da hipótese de que, ao olhar para si e para o cotidiano de suas próprias comunidades, produz-se subjetividades que constroem e circulam mensagens a partir "de dentro". Utilizando como aporte teórico os conceitos da Comunicação Comunitária, fizemos uma análise a partir das ondas ou gerações em que se construiu esse campo de ação e reflexão e traçamos um paralelo com o histórico da Rede. Recorremos, como técnicas de coleta de dados, à observação participante e à pesquisa bibliográfıca.
\end{abstract}

Palavras-chave: Comunicação Comunitária. Autorrepresentação Audiovisual. Projeto Saúde \& Alegria. Rede Mocoronga. Coletivo Jovem Tapajônico.

\begin{abstract}
The Community Communication is a process of popular struggle not only to make people to put themselves on someon's shoes but also for social transformation and political influence. Given the technological advances and the popular use of mobile phones devices, a reflection on new ways of communicating is necessary. This article aims to do a research about audiovisual self-representation from inside out of Rede Mocoronga de Comunicação Popular. It is based on the hypothesis that, by looking at ourselves and the daily life of our own community, we produce subjectivities that build and circulate massages from "within". Using the concepts of Community Communication as a theoretical basis, we analysed the waves or generations in which this field of action and reflection was built and drew a parallel with the history of Rede Mocoronga. As data collection techniques, we used participant observation and bibliographic research.
\end{abstract}

Keywords: Community Communication. Audiovisual self-representation. Projeto Saúde \& Alegria. Rede Mocoronga. Coletivo Jovem Tapajônico.

\section{Introdução}

As mídias comunitárias surgiram em meados do século XX na América Latina no bojo dos movimentos sociais da época e caracterizavam-se originalmente pelo uso mais politizado de meios de comunicação analógicos. No século XXI, diversificaram-se buscando adequação às pautas e comunidades diversas,

\footnotetext{
1 Mestre em Mídia e Cotidiano pela Universidade Federal Fluminense (UFF) e pós-graduada em Cinema e Documentário pela Fundação Getúlio Vargas (FGV). É jornalista e atua como produtora e pesquisadora audiovisual.

2 Doutora em Comunicação e Cultura pela Universidade Federal do Rio de Janeiro (UFRJ) e mestre em Comunicação pela mesma universidade. É professora adjunta e pesquisadora da UFF, na qual está vinculada ao Departamento de Comunicação Social e ao Programa de Pós-graduação em Mídia e Cotidiano.
} 
ligadas ou não a movimentos sociais e de base, mas sempre voltadas para minorias. Atualmente, elas passaram a incorporar as mídias digitais e a produzir novas maneiras de comunicar, apropriando-se da tecnologia e dos dispositivos móveis.

Este artigo concentra-se na análise bibliográfica do campo da Comunicação Comunitária no Brasil e, a partir do conceito de geração, estrutura-se em três ondas para traçar um paralelo entre o histórico da mídia participativa e a atuação da Rede Mocoronga no Baixo Tapajós. Na "Primeira Onda Comunitária", os avanços tecnológicos e o aumento do acesso às câmeras marcam o início das ações comunicacionais comunitárias, sementes da Mocoronga. A "Segunda Onda Comunitária" traz o período seguinte à chegada da Comunicação Comunitária no Brasil e a criação da Rede Mocoronga de Comunicação Popular e das oficinas de formação de jovens repórteres em 1998. E a "Terceira Onda Comunitária" apresenta um salto na perspectiva da autorrepresentação e é marcada pelo fato dos próprios produtores possuírem, dominarem e circularem conteúdos elaborados com os celulares e mídias digitais apesar do acesso não universal à tecnologia.

Além de tratar dos códigos, normas e ideologias da cultura popular, a Comunicação Comunitária lança luz sobre o desejo de emancipação do sujeito cujas relações sociais estão subordinadas às lógicas da produção industrial e da hegemonia do capital; sendo um conjunto de ações políticas que faz das periferias não só espaços de contraposição aos centros de poder, mas um centro de geração de poder popular a partir da comunicação.

A nomenclatura da Comunicação Comunitária mudou ao longo do tempo para contemplar novas especificidades e práticas. As mídias comunitárias já foram chamadas de alternativa, popular, local, cidadã, entre muitos nomes. No Brasil, a consolidação do termo "comunitário" deve-se a muitos fatores e, entre eles, destaca-se especialmente a ação de advocacy da Associação Mundial de Rádios Comunitárias (AMARC). Assim como o nome, a história da Comunicação Comunitária passou por transformações significativas nos últimos cinquenta anos.

Neste trabalho, a partir do conceito de geração do teórico Karl Mannheim, o histórico do campo e das ações comunicacionais do Projeto Saúde \& Alegria (PSA), nome fantasia da ONG Centro de Estudos Avançados de Promoção Social e Ambiental (CEAPS), foi categorizado em ondas, ou gerações, com a finalidade de refletir sobre a autorrepresentação das juventudes ribeirinhas tapajoaras das comunidades atendidas pela organização. 
Para Mannheim (1993), o que caracteriza uma geração é o sentido de experiência compartilhada por indivíduos que ocupam a mesma posição geracional. Nesse sentido, ele propõe um olhar sobre o problema das gerações a partir de três conceitos: posição geracional, conexão geracional e unidade geracional, opondo-se à abordagem que privilegia apenas o tempo cronológico. Segundo Weller (2010), o autor compara a "vertente positivista", predominante entre o pensamento liberal francês de sua época, com o "pensamento histórico-romântico" alemão, alegando que ambas as correntes abordam o tema de maneira diversa. Enquanto a corrente histórico-romântica prefere uma abordagem quantitativa, os positivistas analisam o problema do "ser-humano" através da captação de dados qualitativos.

Essa posição é criticada por Mannheim, que discordava da tentativa de se criar uma lei geral (e equivocada) para "o ritmo da história a partir do determinante biológico da duração limitada da vida de um indivíduo, do fator idade e de suas etapas", que na época giravam em torno dos trinta anos.

A história das ciências humanas aparece nessa caracterização como se houvessem sido estudadas apenas as tabelas cronológicas históricas. Após essa simplificação, a dificuldade do problema parece residir apenas sobre este aspecto: encontrar o tempo médio no qual uma geração anterior é substituída por uma nova na vida pública [...] A duração da geração é determinada de forma diversa a cada momento (MANNHEIM apud WELLER, 2010, p. 511).

A posição geracional proposta pelo autor ressalta o conjunto de oportunidades às quais os sujeitos têm acesso em determinado momento histórico. Ao se envolverem em práticas concretas e compartilhadas, os indivíduos estabelecem uma conexão geracional. Já a ideia de unidade geracional enfatiza as formas pelas quais esses sujeitos respondem aos problemas do seu tempo. Tomando por base essa perspectiva, proponho um olhar sobre a Comunicação Comunitária a partir da ideia de gerações.

Não se trata, portanto, de uma visão engessada sobre as experiências que se desenvolveram ao longo do tempo, ou de uma tentativa de classificação estanque. A proposta é observar os movimentos da Comunicação Comunitária a partir das oportunidades, dos problemas e das respostas dadas pelos sujeitos em contextos específicos. Nesse sentido, a primeira geração surgiu a partir dos movimentos de 1960/1970 até 1980, período em que sobressai o apelo educativo. A segunda, a partir de 1990, destaca-se em relação aos esforços de mobilização 
comunitária. Já a terceira geração é marcada pela apropriação popular das novas mídias em decorrência tanto do desenvolvimento econômico e tecnológico como das mudanças geracionais, sobretudo a partir de meados da década de 2000.

No entanto, vale destacar que essa sistematização não pretende ser uma maneira única e arbitrária de delimitar a Comunicação Comunitária, mas que foi adotada para auxiliar a compreensão epistemológica tanto da área como dos modos de comunicar tapajoara, já que à medida que os momentos históricos transformam os sujeitos, estes modificam seus cotidianos. Uma onda não se sobrepõe à outra. Bem como a identidade cultural de um indivíduo, a comunidade e a Comunicação estão em constante transformação e interação com as suas próprias mudanças.

Hoje, é possível produzir com mais autonomia narrativas de si por si próprio, para si e para o outro. Os logotipos do Projeto Saúde \& Alegria, da Rede Mocoronga e do Coletivo Jovem Tapajônico (Figura 1) mostram o deslocamento institucional. No primeiro logotipo, destaca-se a presença da figura externa às comunidades a partir do palhaço; no segundo, o palhaço une-se à comunidade, palhaço e três crianças (rádio, filme e jornal); já o terceiro logotipo é representado por um ribeirinho. A transformação dos logotipos representa também as ondas da Comunicação Comunitária no Brasil.

\section{Figura 1 - Logotipos do Projeto Saúde \& Alegria (1987), da Rede Mocoronga (1998) e do Coletivo Jovem Tapajônico (2018)}
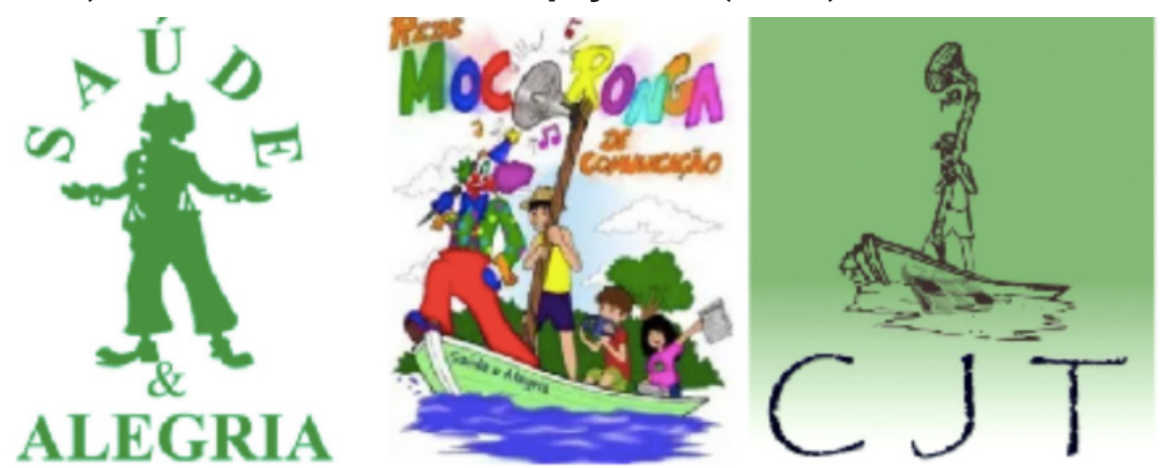

Fonte: Materiais de divulgação

Em A identidade cultural na pós-modernidade, Stuart Hall (2006) recupera três concepções identitárias para discutir o deslocamento cultural do sujeito desde o período pré-moderno até hoje. Na obra, o escritor ressalta a necessidade de se compreender que, ao invés de "falar da identidade como uma coisa acabada, deveríamos falar de identificação e vê-la como um processo em an- 
damento", apesar de a sua fragmentação ter aumentado após a ruptura com o passado monárquico e o nascimento do "indivíduo soberano", ao que atribui possivelmente como "o motor que colocou todo o sistema social da 'modernidade' em movimento":

Isso não significa que nos tempos pré-modernos as pessoas não eram indivíduos, mas que a individualidade era tanto "vivida" quanto "conceptualizada" de forma diferente. As transformações associadas à modernidade libertaram o indivíduo de seus apoios estáveis nas tradições e nas estruturas. Antes se acreditava que essas eram divinamente estabelecidas; não estavam sujeitas, portanto, a mudanças fundamentais (HALL, 2006, p. 25).

Segundo Stuart Hall, a identidade é formada na "interação entre o eu e a sociedade", e cada um desses sujeitos é fruto "dos valores, sentidos e símbolos - a cultura" do mundo e tempo que habitam. Para tanto, o autor define o deslocamento da identidade antes, durante e após a Modernidade nos seguintes conceitos: sujeito do lluminismo, sujeito sociológico e sujeito pós-moderno. Em "ideias bem simplificadas" (ibid., p. 24), a partir da perspectiva da interatividade social, o sujeito do lluminismo é definido como unificado e estável; o moderno diferencia-se pelo caráter interativo ou sociológico; e o sujeito pós-moderno caracteriza-se pelo descentramento e descontinuidades do indivíduo.

O autor destaca que o sujeito pós-moderno finaliza a transição de uma "identidade fixa, essencial ou permanente" (ibid., p. 12) para "identidades abertas, contraditórias, inacabadas, fragmentadas" (ibid., p. 46). Como ele caminha em paralelo ao desenvolvimento tecnológico, a sua fragmentação intensifica-se a ponto de descentrá-lo pelo processo de globalização e de pluralização da identidade emergentes na década de 1970:

A identidade torna-se uma "celebração móvel": formada e transformada continuamente em relação às formas pelas quais somos representados ou interpelados nos sistemas culturais que nos rodeiam (Hall, 1987). É definida historicamente, e não biologicamente (ibid, p. 11-12).

Dentre os acontecimentos históricos despertados pelas manifestações de 1968, Hall destaca o feminismo como um dos principais descentramentos que provocaram mudanças conceituais do indivíduo. Para além, com o slogan "O pessoal é político", abriu espaço para cada movimento reivindicar sua identidade, fun- 
dando a "política de identidades", e para questionar o "privado" e o "público" ao evidenciar no debate social questões até então tidas como "novas", como família, sexualidade e divisão doméstica do trabalho (ibid., p. 45).

Se sentimos que temos uma identidade unificada desde o nascimento até a morte, é apenas porque construímos uma cômoda estória sobre nós mesmos ou uma confortadora "narrativa do eu" (veja Hall, 1990). A identidade plenamente unificada, completa, segura e coerente é uma fantasia (ibid., p. 13).

De acordo com Hall, uma das principais fontes de identidade cultural no mundo moderno são as culturas nacionais. "Ao nos definirmos, algumas vezes dizemos que somos ingleses ou galeses ou indianos ou jamaicanos", como se apenas onde nascemos constitui-se nossas identidades ao "pensarmos nelas como se fossem parte de nossa natureza essencial" (ibid., p. 46). Logo, a formação de uma cultura nacional é uma forma de criar padrões para inserir e subjugar os sujeitos através de uma cultura homogênea.

As culturas nacionais são compostas não apenas de instituições culturais, mas também de símbolos e representações. Uma cultura nacional é um discurso - um modo de construir sentidos que influencia e organiza tanto nossas ações quanto a concepção que temos de nós mesmos [...] constroem identidades (ibid., p. 50).

A Comunicação também desempenha papel estrutural. Sodré (2014) explica que o verbo comunicar está ligado ao sentido das ações de vincular, de organizar, ou ainda, de deixar-se vincular e organizar pelo que há de comum. A função comunicativa que constitui a condição humana deriva desse fenômeno. Como afırma o pesquisador, os homens são comunicantes porque estabelecem relações ou porque organizam mediações simbólicas, de modo consciente ou não, em nome da partilha de algo em comum, e esse comum é a própria Comunicação Comunitária, e o seu núcleo é a comunidade.

\section{Primeira Onda Comunitária}

A primeira onda, ou geração, da Comunicação Comunitária no Brasil é marcada pelo período de sucessivos governos militares, que vai de 1964 até 1985. A partir da ideia de "comunidade imaginada" de Anderson (apud HALL, 2006, p. 
47), vale notar que a comunicação contra-hegemônica irrompe sua disputa no momento em que o regime ditatorial no país é forjado e reforçado ao tecer um discurso pátrio de caráter autoritário e violento. Como achaca o samba-enredo História Para Ninar Gente Grande (G.R.E.S. ESTAÇÃO PRIMEIRA DE MANGUEIRA, 2019), "tem sangue pisado atrás do herói emoldurado".

A identidade nacional é usada como ferramenta de controle da subjetividade social a partir de uma narrativa de nação, reforçando ou criando uma tradição e uma identidade "natural" aos brasileiros calcada em um mito fundacional e na ideia de um povo original (HALL, 2006, p. 55), como, por exemplo, o quadro $A$ primeira Missa no Brasil, pintado por Victor Meirelles em 1860. Uma das pinturas mais conhecidas e onipresente em livros de História do país, ela descreve a "chegada" dos europeus como descoberta, e não invasão ou o início de uma guerra permanente que se instaura em 1500 e atualiza-se até hoje.

Em diálogo com a carta de Pero Vaz de Caminha, a obra legitima a exploração sanguinária dos povos originários e reforça a narrativa de uma nação arquitetada em páginas e personagens ausentes. Outro ponto apontado na obra de Hall que compõe o imaginário brasileiro em relação ao "descobrimento" é a idealização de um povo originário. De acordo com o autor, "a identidade nacional é também muitas vezes simbolicamente ancorada na ideia de um povo ou folk puro, original. Mas, na realidade do desenvolvimento nacional, é raramente esse povo (folk) primordial, que persiste ou que exercita o poder" (p. 55-56).

O escritor Kaká Werá ${ }^{(2010)}$ ressalta que o povo brasileiro é genuinamente indígena, porém não há esse entendimento ou não se admite essa identidade. Apesar do reconhecimento dos indígenas como folk, os povos originários há 520 anos reivindicam presença nas esferas de poder. E, para além da falta de representatividade que os encerra no que Aílton Krenak (2019, p. 23) definiu como "periferia da humanidade", vale perguntar: que indivíduo cabe a definição de indígena? Quem são e como são representados?

Poucos anos após o retrato do nosso "marco civilizatório", o governo brasileiro criou, em 1910, o Serviço de Proteção ao Índio (SPI)4 para "transformá-los" em cidadãos. Assim como, em 1967, a Fundação Nacional do Índio (Funai) ${ }^{5}$ foi criada para "proteger" os povos originário. No entanto, ao incorporar essas populações

\footnotetext{
${ }^{3}$ Kaká Werá foi convidado para o TEDx VilaMadá, em 2010, para trazer a perspectiva indígena ao evento a partir de seu relato sobre o projeto Oca Escola. Ver Werá (2010).

${ }^{4}$ Disponível em: http://www.funai.gov.br/index.php/todos-presidencia/2164-o-servico-de-protecao-aos-indios. Acesso em: 20 abr. 2020.

${ }^{5}$ Disponível em: http://www.funai.gov.br/index.php/quem-somos. Acesso em: 20 abr. 2020.
} 
ao sistema sem preservar suas identidades, apenas legitimou-se um outro tipo de genocídio - um etnocídio -, em constante atualização.

Desde 1970, "as identidades nacionais estão se desintegrando, como resultado do crescimento da homogeneização cultural e do 'pós-moderno global'" (HALL, 2006, p. 69), ao passo que "outras formas de comunicação ganham mais visibilidade social e acadêmica [...] Essa repercussão não se deu ao acaso. Existiu toda uma dinâmica, um conjunto de fatores histórico-sociais que favoreceram esse movimento" (VOLPATO, 2014, p. 218).

A Comunicação Comunitária surge no Brasil no período descrito acima através de mídias de rádios, jornais e vídeos comunitários e alicerça-se entre 1970 e o início de 1990 "no âmbito dos movimentos populares, das organizações de base, da imprensa alternativa, da oposição sindical metalúrgica, de ONGs, de setores progressistas da igreja católica ou realizada por militantes articulados em núcleos de produção audiovisual" (PERUZZO, 2006, p. 5). Seus objetivos situam-se no âmbito das disputas pelos direitos fundamentais, desde a democracia até a alfabetização à distância, buscando "dar conta de desafios sociais e políticos, não de desafios tecnológicos" (BROCK; MALERBA, 2017, p. 13).

As motivações das rádios consideradas pioneiras estavam mais ligadas à garantia de direitos sociais básicos [liberdade, educação, moradia, terra etc.]. Porém, como justiça social não se faz sem disputa política, um segundo momento das rádios comunitárias e livres latino-americanas - sem abandonar suas pautas iniciais - foi abarcar causas mais diretamente ligadas à reconfiguração do poder em suas comunidades e/ou na vida nacional (ibid., p. 13).

Segundo o pesquisador Luiz Dioclécio (2011), "o Brasil foi um dos últimos países da América Latina a embarcar nas ondas das Rádios Comunitárias", e aqui elas podem ser organizadas em três concepções que "muitas vezes se confundem" ainda hoje: rádios revolucionárias, marcadas pela contestação política; rádios sob controle da Igreja Católica, que, apesar do cunho educacional contra-hegemônico, não tiveram o caráter rebelde das rádios católicas que vieram antes na América Latina; e as rádios livres, que pelo caráter anárquico possuíam diferentes formatos e objeções a cada experiência.

A rádio comunitária "Novo Rumos", ou cidadã, como propõe chamar José Lopes Gil (2008 apud DIOCLÉCIO, 2011), é considerada a pioneira no país. Ela surge em 1991 no Rio de Janeiro e, assim como outras, ficou ilegal até o sancionamento 
da Lei n 9.612, em 1998, que, apesar de possibilitar a saída da clandestinidade, não garantiu o fim da repressão. Em outro ritmo, devido às limitações sociais, econômicas e tecnológicas, nesse mesmo período, no Brasil, aparecem as primeiras iniciativas de jornalismo comunitário, como o União da Maré, fundamentais para 0 Cidadão (FELIX, 2008, p. 76-78) e as experiências de Andrea Tonaci que inspiraram a criação do projeto Vídeo Nas Aldeias (ALVARENGA, 2004, p. 60).

Paiva (2007) lembra os dois movimentos fundamentais, apontados pelo filósofo Richard Rorty, a partir dos quais a comunicação comunitária pode operar uma verdadeira revolução linguístico-pragmática: recontar a história e redescrever a si próprio. O movimento de criar sua autorrepresentação, distanciada dos estereótipos, e de apropriar-se de sua história, desconstruindo as narrativas hegemônicas, são as duas estratégias a partir das quais as minorias dão voz à sua mensagem contra-hegemônica (FELIX, 2008, p. 75).

A primeira onda da Comunicação Comunitária elabora uma nova visibilidade a questões urgentes, porém antigas; e/ou emergentes, mas abafadas deflagradas pela política de identidades. Neste período, o Saúde \& Alegria inicia sua atuação fomentando processos participativos de desenvolvimento comunitário e sustentável na Amazônia em 1987 e, no ano seguinte, além do atendimento médico, incorpora a comunicação como ferramenta de educação e mobilização através da produção de cartilhas e atividades artísticas ribeirinhas até formar na década de 90 a Rede Mocoronga de Comunicação Popular.

\section{Segunda Onda Comunitária}

A partir da segunda metade da década de 1990, como em nenhum outro momento no Brasil, podemos detectar uma série de iniciativas envolvendo grupos que encontram, ao "alcance das mãos", um equipamento de vídeo digital, que lhes permite atuar como produtores de imagens. Diferente do que acontece no jornalismo televisivo ou no documentário brasileiro mais contemporâneo, o que parece interessante nessas imagens não é exatamente a forma como as entrevistas são conduzidas, ou seja, as tipologias de interpelações que os entrevistadores propõem aos personagens; nem mesmo a maneira como os entrevistados se saem das perguntas ou provocações verbais dos diretores. O que interessa aqui é, sobretudo, a emergência de um determinado cotidiano compartilhado entre aqueles que participam da realização de um vídeo (ALVARENGA, 2004, p. 13). 
A Segunda Onda da Comunicação Comunitária é marcada pelo estabelecimento das novas formas de comunicar contra-hegemônicas. Tendo em vista que as mídias comunitárias constituem-se, antes de tudo, como atores políticos (BROCK; MALERBA, 2017, p. 210), na década de 1990, o acesso aos meios tornou-se mais tangível do ponto de vista econômico e tecnológico e possibilitou uma maior horizontalização de rádios, jornais, programas de TV e projetos ligados ao cinema através da participação da periferia na produção da informação.

Sodré (2002) tratou do processo de abalo das formas organizadas de mediação do conflito social (como sindicatos, partidos políticos e demais instituições da sociedade civil) relacionando-o à midiatização da sociedade e a um novo regime de identidade político-partidária centrada na imagem espetacularizada, ou seja, na pura aparência: a chamada "despolitização" midiática ou tecnológica resulta, por sua vez, do enfraquecimento ético-político das antigas mediações e do fortalecimento da midiatização. "[...] A tecnointeração toma o lugar da mediação desviando os atores políticos [...] para performance imagística" (ibid., p. 34). 0 conceito de midiatização sintetiza uma nova maneira de o sujeito estar no mundo, uma "tecnologia de sociabilidade ou um novo bios [o midiático], uma espécie de quarto âmbito existencial, onde predomina [...] a esfera dos negócios, com uma qualificação cultural própria (a "tecnocultura")" (ibid., p. 25). A mutação tecnológica estaria no centro de uma outra mutação, sociocultural: a mídia articulada orgânica e sistemicamente com as tradicionais instituições sociais implicaria a reordenação das antigas instituições e a formação de novas formas de sociabilidade (MALERBA, 2016, p. 305).

Para Sodré (2002), os meios de comunicação criaram uma nova esfera existencial que não permite pensar as tecnologias dissociadas de seu caráter ideológico. As técnicas, como assinala o autor, não são neutras, mas se constituem a partir de esferas de poder, regidas pela lógica do capital. A utilização das novas tecnologias da informação e da comunicação precisa ser pensada, portanto, dentro de seu duplo movimento: como potência para dar visibilidade às histórias e demandas de sujeitos periféricos, bem como aparato de controle e exercício de um poder a serviço do capital.

O Projeto Saúde \& Alegria criou a Rede Mocoronga de Comunicação Popular em 1998, ano em que as rádios comunitárias foram legalizadas no país, apostando no envolvimento popular. A Mocoronga nasce estruturando-se como uma rede de rádios-poste e jornais comunitários implementados nas comunidades ribeirinhas e alimentados pelos próprios moradores. 0 conteúdo era produzido em oficinas de formação técnica para os ribeirinhos, em sua maioria jovens. 
Vale destacar que a edição dos programas de rádios e editoração e impressão dos jornais eram feitas na sede da Rede Mocoronga, que funcionava como uma matriz de onde os produtos finalizados eram distribuídos para as comunidades de origem, espécie de sucursais.

As oficinas da Mocoronga surgem com o intuito de partilhar o fazer e o produto com as comunidades para que elas fossem contempladas pelas histórias contadas. Como a proposta deste estudo é problematizar a formação técnica em audiovisual, concentrarei a discussão teórica no Vídeo Comunitário, que desponta na segunda geração da Comunicação Comunitária, mas é introduzido na Mocoronga apenas em 2011. No entanto, vale retomar o cenário que antecede as oficinas de vídeo da Mocoronga para compreender como a câmera passou de fato para a mão do povo.

A concepção de vídeo popular, tal como descrita por Luiz Fernando Santoro, nasce embebida no espírito vanguardista dos últimos anos da década de 1960, na Europa. Para refazer esse trajeto, o autor cita declaração de Jean-Luc Godard, em uma semana sobre o cinema político, na época, em Montreal. "Quero dizer ao público, inicialmente, que ele não possui esse instrumento de comunicação - ainda nas mãos dos 'notáveis' -, mas que poderá servir-se dele se thes derem oportunidade para dizer e ver o que quiser, e como quiser" [...] Santoro acrescenta outra importante atuação de Godard que, em 1969, em uma reunião na Universidade de Vincennes, teria oferecido um equipamento de vídeo aos estudantes, propondo que estes "tomassem em mãos um dos instrumentos do poder" (ALVARENGA, 2004, p. 44).

Essa proposição marca as primeiras ideias do Vídeo Militante após 1968, atravessa o Vídeo Popular em 1980 e efetiva-se apenas na década de 1990 com o Vídeo Comunitário:

As estratégias e táticas adotadas na primeira fase de atuação desses movimentos, que chama de pré-política, previam ações violentas, já que o diálogo e as negociações eram inviáveis durante a repressão promovida pelo regime militar. Em um segundo momento, que remete às três últimas décadas, ocorreu o que Gohn chama de "formas de ação modernas", que incluem o uso da câmera de vídeo e demais recursos de comunicação. "A câmera de vídeo foi um instrumento importantíssimo para registrar eventos dos movimentos populares nos anos 1980, assim como para desenvolver projetos de educação popular e formação de lideranças." As experiências brasileiras realizam uma síntese, não apenas do que aconteceu na Europa e no Canadá, mas também de experiências brasileiras anteriores, que enfatizavam a questão da participação (ibid., p. 47). 
De acordo com a pesquisadora Clarisse Alvarenga, os três movimentos possuíam ligação entre si, no entanto, no Brasil a ideia de "recriar a noção de 'comunidade' por meio de um dispositivo eletrônico" não dependia da "evolução tecnológica", e sim da escolha "dos realizadores" pela participação da periferia como sujeito político, o que fica visível a partir da chegada da tecnologia do vídeo ao país em 1974:

Santoro avalia que seria "difícil acreditar que as emissões de caráter comunitário, por si só, fossem capazes de formar uma comunidade, como também é ilusório pensar que esses novos instrumentos em mãos de grupos isolados, sem estarem a serviço de um movimento social determinado que justifique sua utilização, possam ser eficazes". Estava claro que não existiria uma relação direta entre o uso da tecnologia do vídeo e os ideais revolucionários. A proposta do vídeo militante será, então, retomada, na década de 1980, pelos líderes do movimento do vídeo popular na América Latina para configurar uma prática distinta, que nem por isso deixa de se apropriar das características mais marcantes do vídeo militante (ibid., p. 45).

Tal como o Vídeo Militante, o desafio continuava sendo a participação popular ativa nos processos de produção e veiculação das imagens. No Brasil, o Vídeo Popular ligou-se à preservação da memória, divulgação e expressão dos movimentos políticos de esquerda como, por exemplo, o registro do I Congresso Nacional da Classe Trabalhadora (CONCLAT), em 1983. Da perspectiva da produção cultural, Luiz Fernando Santoro (1986) destaca que o movimento supriu um vazio estabelecido diante do alto custo do material cinematográfico e da inexistência de uma televisão com projeto democrático de participação.

No entanto, do ponto de vista da recepção, os vídeos da Associação Brasileira de Vídeo Popular (ABVP) não contemplaram a atuação popular. No estudo Transformações no Vídeo Popular, Henrique Luiz Pereira Oliveira (apud ALVARENGA, 2004) observa que apesar de ter sido distribuído num circuito paralelo ao dos meios de massa da época, o Vídeo Popular "típico" (ibid., p. 55), como chamou Oliveira, foi protagonizado mais pelo pensamento das lideranças partidárias do que propriamente uma manifestação do povo. A ABVP surgiu em 1984 e centralizou o movimento no país até 1995, quando deixou de produzir vídeos com a chegada dos equipamentos digitais mais acessíveis financeiramente, e encerrou suas atividades oficialmente em 2001, concomitante à implantação dos canais a cabo no Brasil. O fım da associação desencadeou o Midiativismo, o Vídeo Comunitário, entre outros movimentos que, em geral, através de oficinas de formação descons- 
truíram o modelo sociológico do Cinema Documentário e possibilitaram a produção compartilhada desejada pelas mídias comunitárias desde a década de 1960.

A apropriação dos equipamentos por parte de grupos leigos pode vir a acontecer de maneira espontânea ou através de um estímulo externo. Pode ocorrer também de forma eventual ou regular, desenvolvendo-se ao longo do tempo. [...] Em geral, esse tipo de atuação é atribuído a ONGs (Organizações Não Governamentais) ou a associações localizadas na esfera da sociedade civil que contam com patrocínio de empresas privadas ou públicas. Entretanto, há também ações nesse campo empreendidas pelo Estado, como política pública, por produtoras de cinema e vídeo e por empresas privadas especializadas em prestar serviços na área (ALVARENGA, 2004, p. 16).

Segundo Alvarenga, o Vídeo Comunitário fomentou uma "espécie de pacto entre aqueles que participam da realização de um filme, ativando a formação de uma comunidade ao redor deles - sejam eles quem for" em "grupos localizados em áreas urbanas, como vilas, favelas, bairros periféricos de centros metropolitanos, bem como em áreas rurais, tais como projetos de vídeo desenvolvidos junto ao MST (Movimento dos Sem Terra), comunidades ribeirinhas, interioranas e aldeias indígenas" (ibid., p. 15).

A noção de vídeo comunitário não estava centrada em uma concepção a priori de sensibilidade estética videográfica, mas no procedimento de envolver, em diferentes níveis, grupos sociais nas diversas situações inerentes ao processo de realização de vídeos, tais como criação de roteiro, produção, gravação, edição e exibição. A intenção foi deixar que a análise dos filmes sofresse alterações decorrentes da diversidade de sensibilidades encontradas, dos referenciais que cada grupo articula, das diferenças que apresentam entre eles. [...] Passar o controle da realização dos vídeos para um grupo de cineastas ordinários, que se utiliza da produção de imagens em movimento para trabalhar suas questões internas e, a partir daí, inseri-las dentro de um universo cultural maior (ibid., p. 18).

Consuelo Lins e Cláudia Mesquita (2008) observam que a intensificação do uso dos meios audiovisuais provocou debates sobre a identidade social e étnica de grupos minoritários a ponto de eles passarem de "objeto" para "sujeito" fílmico e engendrarem processos de constituição de autorrepresentação audiovisual, que difere de autobiografia. O conceito de autorrepresentação aplica-se a uma série de experimentos que, através de oficinas de formação audiovisual, têm como ob- 
jetivo permitir e estimular a elaboração de representações de si pelos próprios sujeitos da experiência, aqueles que eram e ainda são objetos clássicos dos documentários convencionais.

As autoras definem as produções autorrepresentativas como elaboradas "de dentro", por indivíduos que constituem os grupos sociais retratados e estão, de um modo geral, apartados (por sua situação social) dos meios de produção e difusão de imagens. Não se trata, portanto, da perspectiva de um indivíduo que se acredita parte do grupo ou de um olhar que se propõe "interno" sem de fato sê-lo. Nesse contexto, Lins e Mesquita destacam o Vídeo Nas Aldeias (VNA), projeto que nasceu em 1987 dentro do Centro de Trabalho Indigenista (CTI)6. O VNA foi criado pelo indigenista Vincent Carelli, constituiu-se como ONG em 2000 e hoje é a iniciativa mais antiga dentro do Vídeo Comunitário ainda em atividade.

O primeiro experimento realizado pelo Vídeo nas Aldeias envolveu os índios Nambiquara, do Mato Grosso. $O$ ato de filmar um ritual de passagem feminino e, em seguida, exibir para os índios suas imagens gerou o que Vincent chamou de "uma catarse coletiva que acabou numa furação coletiva de nariz e beiço", técnica que eles não utilizavam há mais de 20 anos. A intenção de descrever esse ritual configura, portanto, apenas como um ponto de partida, que é possível ver desdobrar-se ao longo do filme, no momento em que os coordenadores do projeto decidem mostrar as imagens à comunidade, cena inserida na edição final. Mas, se existiu essa abertura para a participação da comunidade, através da projeção das imagens, houve uma retomada do controle do processo por parte dos realizadores que optaram por utilizar uma voz over, explicando que a comunidade de índios não se reconheceu nas imagens, não julgou estar devidamente representada. Por isso, os índios teriam demandado uma segunda gravação do mesmo ritual, sendo que, dessa vez, eles apresentaram a preocupação de se pintar, de utilizar adereços perdidos no tempo e, sobretudo, de retomar a prática de furar o corpo "esquecida" por 20 anos (ALVARENGA, 2004, p. 72).

O trecho acima refere-se ao filme A Festa da Moça, produzido em 1987. O documentário foi a primeira experiência com vídeo do CTI, e o potencial do audiovisual orientou a criação do VNA. As primeiras obras foram feitas pelos coordenadores do projeto junto aos povos originários. Em um segundo momento, em 1998, os diretores iniciaram a formação de realizadores indígenas para que estes pudes-

\footnotetext{
${ }^{6}$ O Centro de Trabalho Indigenista foi fundado em 1979 por Gilberto Azanha junto a outros antropólogos e a educadores para apoiar outros projetos de demarcação territorial, desenvolvimento autossustentado e educação. Vale ressaltar que Azanha participou da expedição para conhecer os Krahô Canela junto a Andrea Tonacci nos primeiros experimentos da atuação indigenista, os quais influenciaram diretamente o VNA (ALVARENGA, 2004, p. 62).
} 
sem gravar, editar, e assinar os vídeos feitos por eles. Assim, o trabalho aconteceu de forma gradual a partir do desenvolvimento metodológico proposto e alterou as narrativas do cenário brasileiro.

Gianni percebeu que difıcilmente chegaria a dar uma visão de um Waiãpi a respeito de um assunto qualquer ou de como um índio Waiãpi se percebe. O Waiãpi também não conseguiria dar um olhar de fora dele mesmo. Nesse momento ainda não havia claramente a proposição de incluir os índios no processo de produção dos vídeos, no projeto Vídeo nas Aldeias. Era um trabalho de gravação, com objetivo de traduzir aquela cultura para o mundo ocidental. Foi a partir desse processo que foi possível detectar o interesse dos índios em participar, ou mesmo um fascínio por aquele instrumento, muitas vezes até um desconcerto em se ver na câmera, perceber-se na TV. O vídeo O Espírito da TV trata dessa relação. "Começa um processo de alteridade muito grande, que é você se confrontar com um outro que é você, mas que é diferente ou que está num lugar diferente. Ou seja, como que a tua imagem, como que você na realidade quer se mostrar, qual que é o teu olhar que você quer passar para os outros. Isso cria todo um outro tipo de ideologia, um tipo de análise, que esse tipo de imagem te permite." Gianni tentou pela primeira vez repassar conhecimentos em vídeo para um índio Waiãpi. Era Kasiripinã, que estava em São Paulo para acompanhar um processo de edição e acabou tendo também contato com a câmera. Saíram juntos pela cidade, para que o índio Waiãpi pudesse começar a fazer gravações. Naquele momento esse processo de repassar conhecimentos para os índios não estava claro. Mas foi um primeiro momento que, mais tarde, foi formalizado e colocado em prática, dentro mesmo do Vídeo nas Aldeias (ibid., p. 83).

O diretor Gianni Puzzo foi um dos professores da primeira oficina de formação técnica para cinegrafistas indígenas no país, no Xingu, e pouco tempo depois, das primeiras oficinas de formação audiovisual para realizadores indígenas. Outra mudança também gradual foi o deslocamento do enfoque nas questões identitárias e de luta pela demarcação territorial para um registro que se aproxima mais o vídeo ao dia a dia, com a câmera na mão. Essa mudança de perspectiva vem de uma reflexão dos coordenadores do projeto e marca a presença do agente externo apesar dos realizadores serem indígenas. O exercício de um olhar mais próximo do cotidiano de Agnes Heller (2004) tenta transmutar a não cotidianidade (estado de suspensão da cotidianidade) dos vídeos que focavam inicialmente nas festas e rituais das aldeias, cuidando para não "folklorizar" ao invés de exteriorizar essas existências, o tecido real da história. 


\begin{abstract}
Queremos afirmar que esses novos equipamentos podem gerar uma outra filosofia se combinados com um tipo de prática voltada para a experimentação social, na qual, muitas vezes, os cineastas se dispõem a ter uma relação mais orgânica com as comunidades envolvidas. E se recentemente as pessoas filmadas puderam passar para o lado da câmera, temos que pensar também que a câmera estaria passando para o lado das pessoas filmadas e seria esse gesto que o vídeo comunitário poderia efetuar: não apenas fazer as pessoas comuns passarem para o outro lado experimentando as gravações, mas colocar a câmera do lado das pessoas comuns, quebrando o eixo no qual esse equipamento esteve historicamente equilibrado (ALVARENGA, 2004, p. 29).
\end{abstract}

É dentro desse contexto tecnológico e narrativo que se iniciam as oficinas de comunicação do PSA. Sendo a educação o fio condutor de todo o trabalho do projeto, para realizar a formação dos grupos locais de jovens, a Rede Mocoronga incorporou uma série de atividades organizadas a partir dos seguintes eixos metodológicos: Gestão e o Fortalecimento Institucional; Gestão Comunitária; Comunicação Comunitária e Inclusão Digital; Protagonismo Juvenil; e Educomunicação. Embora tenha pouca representação no Brasil, a Educomunicação é utilizada como estratégia de fortalecimento das mediações, ainda que em uma sociedade midiatizada.

A Educomunicação pressupõe a participação, a articulação de gerações, setores e saberes, a integração comunitária, o reconhecimento de direitos e a democratização dos meios de comunicação com o maior acesso popular às pautas, à produção e à gestão da comunicação. Mas a comunicação, na perspectiva educomunicadora, não se reduz à educação para a apropriação dos meios. Ela deve estimular, antes de tudo, a emancipação dos cidadãos. Segundo Ismar de Oliveira Soares (2011), o objetivo da Educomunicação é ampliar as condições de expressão dos indivíduos como forma de engajá-los mais ativamente em seu processo educativo. $\mathrm{O}$ autor afırma que ela estimula uma atitude reflexiva e crítica dos indivíduos diante da sociedade e da cultura de massa através da incorporação criativa das tecnologias de comunicação e informação.

Essa é a razão pela qual se afırma que o eixo das relações comunicacionais entre pessoas e grupos humanos converte-se no hábitat natural da Educomunicação. Sua função é a de qualificar tais relações a partir do grau de interação que for capaz de produzir. Conceitos como democracia, dialogicidade, expressão comunicativa, gestão compartilhada dos recursos da informação fazem parte de seu vocabulário. Está presente onde práticas de comunicação se manifestam com consequências para a vida em sociedade: na família, na escola, na empresa, na própria mídia (SOARES, 2011, p. 18).

RCD • ISSN 2674-9246 • n. $5 \cdot$ ano $3 \cdot$ jan./jun. 202 I 
Soares ressalta que a Educomunicação surgiu de uma necessidade dos movimentos sociais de organização da sociedade civil, tendo como meta a construção da cidadania. Para o autor, a Educomunicação é um campo de convergência de todas as áreas das Ciências Humanas, originário de experiências como as de Paulo Freire (2013) junto às ligas camponesas de Pernambuco em 1950. Para ele, há algum tempo o comunicador achava que o educador não tratava de assuntos interessantes, e sim estava preocupado em fiscalizar os jornais.

Apesar de não ter aplicado suas ideias diretamente ao processo de comunicação, Paulo Freire influenciou muitos teóricos da área. Ele acreditava que o ser só se tornava humano ao se comunicar. Além disso, o autor afirmava que, para haver comunicação, o processo de troca de saberes e experiências entre diferentes sujeitos deveria ocorrer em situações de igualdade, em que ambos tivessem o direito de ouvirem e serem ouvidos:

Paulo Freire é incluído entre os pesquisadores de comunicação por um livro - Comunicação ou extensão - escrito em 1968, no Chile. Sem tratar da comunicação massiva, este livro orientou muitas interpretações na área, pois nele está contida a crítica principal aos meios de comunicação de massa: de consistirem em meros instrumentos de transmissão, de tratarem os destinatários como receptores passivos e de impossibilitarem relações dialógicas. O livro Pedagogia do Oprimido confirma Paulo Freire entre os que buscavam compreender os processos latino-americanos pela história não-oficial. Ele dedicava seu livro "aos desamparados do mundo e a quem, descobrindo-se entre eles, com eles sofrem e com eles lutam". Tanto Armand Mattelart como Jesús Martín Barbero afirmam, em suas obras, a contribuição de Freire à construção de suas perspectivas teóricas (BERGER, 2011, p. 256-257).

\section{Terceira Onda Comunitária}

A câmera passou para as mãos de quem sempre foi filmado, no entanto, as produções compartilhadas estão totalmente independentes da interferência, ao menos técnica, de uma organização ou pessoa de fora da comunidade? A experiência de entregar a câmera para o personagem do filme vai além da "palavra emprestada" - que "se emprestamos, podemos tomar de volta" (ALVARENGA, 2004, p. 34)?

A participação tem duas bases complementares: uma base afetiva - participamos porque sentimos prazer em fazer coisas com os outros - e uma base instrumental - participamos porque fazer coisas com outros é mais eficaz que fazê-las sozinhos. Essas 
duas bases - afetiva e instrumental - deveriam equilibrar-se. Porém, às vezes, elas entram em conflito e uma delas passa a sobrepor-se à outra. [...] Promover a participação é importante para eliminar as amarras e recalques impostos por querer ou casualmente pela sociedade. Sem intenção de criticar ou desmerecer outras organizações ou pessoas que atuam em prol da população mais carente oferecendo cursos profissionalizantes, entre outras atividades, acredito que é necessário antes de tudo fomentar o pensamento reflexivo (SILVA, 2011, p. 28-35).

O vídeo enquanto dispositivo de integração estimula a produção compartiIhada, mas é importante ressaltar que a atuação efetiva parte de um desejo próprio, de acordo com os vínculos dos participantes com o projeto. O mesmo ocorre com a palavra. Ela pertence, antes de tudo, ao seu emissor. As oficinas hoje já não são um precedente, mas ainda são um caminho eleito e reivindicado pelos moradores das comunidades atendidas pelo PSA.

Ao longo de toda a convivência que se estabelece entre o projeto e a comunidade, há exibição de filmes, conversas sobre o material e ainda exibições internas do próprio vídeo comunitário ao longo de sua realização. Além disso, essas oficinas precisam ter a motivação necessária para que os alunos participem delas. Na verdade, nem sempre o projeto de realizar um filme está entre os planos da comunidade. É a participação nas oficinas que vai apontar essa possibilidade. É sabido que, com a globalização, as relações de trabalho se modificaram, gerando um encurtamento do tempo livre dos trabalhadores. É escassa a disposição de tempo para atividades paralelas. Talvez por isso, grande parte dos projetos de vídeo comunitário envolva jovens (ALVARENGA, 2004, p. 64).

Como Alvarenga ressaltou, a presença de jovens nas oficinas de Vídeo Comunitário era notável e esse fator estava associado à maior disponibilidade de tempo para investir nesse tipo de atividade. No caso da Rede Mocoronga de Comunicação Popular, esse grupo é inclusive declaradamente o seu público-alvo. A Mocoronga iniciou gradualmente a sua atuação. As oficinas nasceram em 1998 formando jovens para atuarem como "repórteres da floresta" e em 2011 começam as experiências com o audiovisual.

A respeito do cinema verdade, Jean Rouch, cineasta que experimentou o compartilhar das filmagens em várias de suas acepções, disse certa vez que essa modalidade de cinema não prevê uma verdade única, mas uma verdade que surgiria com o filme, uma "verdade do filme". Acreditamos que, no caso do vídeo comunitário, tal como queremos abordar essas experiências, po-

RCD • ISSN 2674-9246 • n. $5 \cdot$ ano $3 \cdot$ jan./jun. 2021 
demos considerar que não se trata de uma comunidade única e preexistente a ser retratada, mas, parafraseando Jean Rouch, de algo como uma "comunidade do filme" (ibid., p. 32).

A palavra engendra "uma comunidade do filme" ao passo em que fortalece a subjetividade dos jovens ribeirinhos no sentido de, em associação aos fatores sociais e à mídia participativa contemporânea, estimular a emergência de grupos que podem ser definidos como unidade de uma geração. O Coletivo Jovem Tapajoara (CJT) é um exemplo do que Karl Mannheim chamou de unidade geracional (generationseinheit). Conforme Weller (2010, p. 210), esses grupos criam laços sem intenção de "constituir uma coesão social, ainda que, ocasionalmente, algumas unidades geracionais possam vir a constituir grupos concretos", tal como o movimento estudantil de 1968. O CJT suscita uma conexão geracional, na medida em que os seus integrantes dão uma resposta em comum aos problemas que encontram ao se apropriarem do que a sua situação geracional disponibiliza.

Em 2018, vinte anos após a criação da Rede Mocoronga, jovens que participam ou participaram da Mocoronga criaram um coletivo próprio, o Coletivo Jovem Tapajônico (CJT). O grupo visa discutir as problemáticas associadas a temáticas sociais, como clima e território, e destaca-se pela luta da juventude em prol do território nas redes. O coletivo dialoga com 13 povos de 76 comunidades e aldeias. Tendo a realidade local como referência, atua produzindo e distribuindo informação através de vídeos, videoclipes, paródias e fotografias divulgados pelo Facebook, e, principalmente, pelo WhatsApp.

Os comunicadores do grupo, em sua maioria, participaram e/ou participam da Rede Mocoronga. Esses jovens, contudo, buscam outros modos de comunicar, de se representar e de se articular politicamente. Cabe aqui sublinhar que o CJT opera independente à Mocoronga, apesar de atuarem em parceria em alguns projetos. A cooperação dos dois grupos marcara as práticas da comunicação ribeirinha ao aproximar a linguagem do cotidiano comunitário e facilitar o entendimento sobre a Covid-19.

No campo, é notória a coexistência desses movimentos. A Mocoronga não ficou obsoleta nas comunidades, tanto que, nas regiões ainda sem acesso à internet, o programa dela na Rádio Rural de Santarém foi o meio de comunicação que, através do rádio de pilha, esteve presente nas comunidades afetadas pela pandemia. As rádios-poste e os telecentros reforçaram as campanhas nesse período, mas são poucos em funcionamento atualmente. Os jornais comunitários perderam a for- 
ça com a conversão digital e as informações produzidas pela Mocoronga em 2021 foram veiculadas basicamente nas redes sociais. Devido ao isolamento social, as oficinas de vídeo e rádio foram substituídas por um concurso de filmes, que devem ser produzidos pelos jovens ribeirinhos com o celular para concorrer ao Mocoroscar.

A Terceira Onda Comunitária é atravessada pela aproximação do vídeo ao cotidiano. Não há uma busca pela participação. Ela é dada, de uma maneira geral, no campo, através da apropriação popular do celular, que passa a ser usado como mídia. Considerando as desigualdades que "distanciam" o Brasil, de uma maneira geral, qualquer pessoa pode gravar um filme a qualquer hora, em qualquer momento e lugar através das novas tecnologias de informação no país. Nota-se que os jovens ribeirinhos da geração digital não só constroem, como circulam suas mensagens a partir "de dentro" da periferia.

Mas isso não quer dizer que esse conteúdo terá visibilidade. Primeiro, vale frisar, que o acesso à web não é universal. Segundo, as plataformas de distribuição dos conteúdos digitais são hegemônicas. Contudo, mesmo a internet não chegando a todas as comunidades e aldeias na Amazônia, os jovens dessas regiões ribeirinhas estão em rede e apostam no potencial dela. É importante levar em consideração que os integrantes desse coletivo para além de serem jovens, são nativos da era digital (geração Z), ponto favorável à autorrepresentação e visibilidade.

Tendo como base Mannheim (1993), é possível enquadrar o CJT como produtor de uma nova cultura, no sentido que é constituído por uma geração que cria uma nova sociedade, que é portadora de uma mudança social. O diálogo intergeracional é um aspecto muito relevante. Talvez nunca tenhamos presenciado a coexistência de tantas gerações distintas. E isso não é só porque as pessoas estão vivendo mais, mas também porque os processos socioculturais têm permitido a emergência de gerações em um ritmo bem mais veloz. O pesquisador lan Dawsey (2019) revela que a chegada das redes digitais no Tapajós alterou a comunicação, autonomia e território dos ribeirinhos a partir da década de 1990.

Se na região do baixo Amazonas os elementos que compõem fisicamente uma aldeia indígena ou uma comunidade quilombola ou ribeirinha é, no mínimo, igreja, campo de futebol, barracão comunitário e escola, é verdade também que não tem há um(a) pajé ou benzedor (benzedeira) ou puxado (puxadeira), não é uma comunidade. E se o especialista for mulher, quase sempre terá também conhecimentos para atuar como parteira. São pessoas comuns, que trabalham e vivem de forma humilde como os demais moradores. Porém, essa simplicidade esconde sua enorme 
importância na vida dessas sociedades. Elas são especiais e imprescindíveis por terem reconhecidamente o dom de curar (VAZ FILHO, 2016, p. 13-14).

Ainda de acordo com o frei e pesquisador Florêncio Almeida Vaz Filho, a pajelança tornou-se um indicador de tradição cultural e crucial para a "tomada de consciência étnico-cultural" nos últimos trinta anos. Para o autor, esses personagens dos povos tradicionais, em particular Laurelino de Takuara, foram essenciais para a resistência, preservação e continuidade da ancestralidade indígena. A morte de Laurelino, conhecido como o "pajé dos Tapajós", marca o início de um importante processo territorial e identitário:

Se o respeitado pajé do grupo afirmou "eu sou índio, não me envergonho disso", por que seus filhos pensariam diferente? Sabendo que os indígenas possuíam direitos, principalmente ao território, foram à FUNAI reivindicar a terra demarcada. Depois, adornaram-se com alguns sinais indígenas exteriores e, portando os símbolos e armas da pajelança, apresentaram-se publicamente. A figura humilde dos pajés e benzedores é um símbolo do que Karl Arenz (2000) chamou de "teimosia da pajelança", essa tradição que silenciava para continuar viva e que se dizia católica para não ser esmagada pelo catolicismo. A pajelança teria permitido que no inconsciente coletivo nativo persistisse um núcleo que preencheria um significado central no processo de emancipação social constituída pela reorganização indígena. [...] Por isso, mais do que um conjunto de crenças ligadas aos encantados, a pajelança pode ser vista como o sistema interpretativo dos indígenas e ribeirinhos amazônicos (descendentes dos indígenas em sua maior parte). Apesar da colonização e da catequese cristã, a pajelança continuou desempenhando esse papel ao longo dos séculos, não de forma imutável, mas adaptando-se e recriando-se. Ainda hoje, ela fornece as lentes, através das quais eles veem o mundo; e a linguagem, através da qual expressam sua visão sobre a realidade e seus anseios de emancipação (ibid., p. 40-41).

A palavra comunidade foi introduzida pelas missões católicas na década de 1950 para denominar "todos os vilarejos ribeirinhos e as margens das rodovias" e pode ser entendida na região como a "reunião efetiva de um grupo de famílias que vivem próximas" organizadas "por líderes eleitos entre seus membros" (VAZ FILHO, 2016, p. 13). No entanto, em 1990, a Igreja Católica, que outrora silenciou e perseguiu os pajés na região, apoia o movimento de luta dos comunitários que passam a reivindicar sua história e origem indígena, substituindo gradualmente "o termo comunidade por aldeia" (VAZ FILHO, 2010, p. 245). 
O movimento indígena, reivindicando identidade e território, iniciou-se em 1998, na Flona Tapajós, com uma comunidade declarando-se Munduruku. Logo outras comunidades nos rios Tapajós, Arapiúns e Maró se assumiram indígenas e o movimento cresceu, e não apenas em virtude dos direitos dos povos indígenas, respaldados por legislações internacionais e pela Constituição de 1988, em um quadro de insuficiência de serviços públicos para as comunidades caboclas. Concorre também o desejo de pertencer a um povo, a um lugar e a uma luta (PEIXOTO; ARENZ; FIGUEIREDO, 2012, p. 279).

Esse processo de retomada de tradições por grupos étnicos, então considerados aculturados ou extintos, é chamado de etnogênese. Entre os moradores tapajoaras, é conhecido também como ressurgência e é atravessado por uma questão política relevante: o reconhecimento da ancestralidade indígena desses povos apresenta-se como ameaça à exploração econômica das reservas "protegidas" pelo Estado. A ressurgência não é um processo recente, mas ainda gera muitas divergências, até éticas, relacionadas à temática.

O conceito também foi criticado por alguns entrevistados. O cacique de Vila Franca, Abraão Atman, questionou: "Ressurgência? Ressurgi de onde? Do inferno? Eu sempre fui daqui, minha raiz é essa terra e ela é indígena. Sempre foi. Vocês que invadiram." Ex-aluno de graduação em História na Universidade Federal do Oeste do Pará (UFOPA) e cineasta, Atman aposta na produção de narrativas, contudo, sempre busca frisar que seu povo "não sumiu, foi silenciado". Como afırmou Walter Kumaruara7 no Instagram, em 2019: "Se o meu lado da comunidade não resistir, eu deixo de existir. Não nego a minha existência e sempre lutarei pelos meus."

Apesar do campo ser marcado pelo que Martín-Barbero (2001) chamou de "destempo", a alternância de gerações, tanto no que diz respeito às disputas que emergem das relações de poder quanto aos processos de reprodução social, contribuiu para os ribeirinhos postularem seu lugar e suas pluralidades nos espaços midiáticos, mesmo que hegemônicos.

Kilomba toca num tema essencial quando discutimos lugares de fala: é necessário escutar por parte de quem sempre foi autorizado a falar. A autora coloca essa dificuldade da pessoa branca ouvir, por conta do incômodo que as vozes silenciadas trazem, do confronto que é gerado quando se rompe com a voz única. Necessariamente, as narrativas daquelas que foram forçadas ao lugar do Outro serão narrativas que visam trazer conflitos necessários para a mudança. 0 não ouvir é a tendência a permanecer num lugar cômodo e confortável daquele que se intitula poder falar sobre os Outros, enquanto esses Outros permanecem silenciados (RIBEIRO, 2019, p. 54).

7 Walter Kumaruara é um jovem ativista indígena e um dos fundadores do coletivo Jovem Tapajônico, no Pará. 


\section{Conclusão}

A concepção de comunidade mudou ao longo do tempo, mas enquanto a noção ligada ao espaço geográfico foi superada, o sentimento de pertença, a participação, a conjunção de interesses e a interação persistiram. A Comunicação Comunitária resiste como uma fresta que o mercado não consegue dominar. Segundo Sodré (2014), o mercado pode controlar o "comum midiatizado", mas ele não consegue dominar o homem e o conflito que emerge no interior de uma comunidade, o que pode ser um caminho de resistência, principalmente quando conjugado às tecnologias de comunicação e informação.

Ao definir essas gerações e exemplificar cada uma delas com a história do PSA e a participação da juventude ribeirinha, é possível refletir sobre como esses jovens vão conseguindo se autorrepresentar cada vez mais. A cada geração, essa autonomia vem da tecnologia muito mais do que em função da ONG - que também não quer dizer que a participação é maior ou melhor. Acompanhar a transformação da primeira à terceira geração da Comunicação Comunitária possibilita compreender que a evolução da autorrepresentação acompanha as mudanças tanto da tecnologia quanto das juventudes.

A apropriação do celular como ferramenta de produção de conteúdo possibilita novas trocas. Por um lado, ela não garante emancipação política nem impede um esvaziamento do sentido das enunciações. Por outro, é uma ferramenta que horizontaliza a comunicação. Um perfil nas redes sociais pode ser uma mídia. O potencial do midiativismo é grande, mas é essencial refletir sobre as maneiras de fortalecer o centro das comunidades para que a Comunicação Comunitária seja efetiva e representativa de fato. A crise da sociedade não é tecnológica, mas de representação.

\section{Referências}

ALVARENGA, Clarisse Maria Castro de. Vídeo e experimentação social: um estudo sobre o Vídeo Comunitário contemporâneo no Brasil. Dissertação (Mestrado em Multimeios) - Instituto de Artes, Universidade Estadual de Campinas (Unicamp). Campinas, 2004. Disponível em: http://www.repositorio. unicamp.br/handle/REPOSIP/284859. Acesso em: 24 jun. 2020.

BERGER, Christa. A pesquisa em comunicação na América Latina. In: HOHLFELDT, Antonio; MARTINO; Luiz C.; FRANÇA, Vera Veiga (Org.). Teorias da Comunicação: conceitos, escolas e tendências. Petrópolis, RJ: Vozes, 2011. p. 241-277. 
BROCK, Nils; MALERBA, João Paulo (Org.). Rádio comunitárias em tempos digitais: reflexões sobre as transformações, inovações e desafios da mídia participativa. Rio de Janeiro: AMARC Brasil, 2017.

CUSTÓDIO, Leonardo. Panorama global da comunicação comunitária como ação política periférica. Revista Mídia e Cotidiano. Niterói: Universidade Federal Fluminense: v. 10, n. 10, dez. 2016. Disponível em: https://periodicos.uff.br/ midiaecotidiano/article/view/9799/6929. Acesso em: 9 ago. 2020.

DAWSEY, Ian Victor Santana. A emergência das redes digitais em comunidades ribeirinhas da Amazônia. Dissertação (Mestrado em Ciências da Comunicação) Programa de Pós-graduação em Ciência da Comunicação da Universidade de São Paulo (USP). São Paulo, 2019.

DIOCLÉCIO, Luiz. A saga das rádios comunitárias no Brasil. In: Encontro Nacional de História da Mídia, 8 abr. 2011. Disponível em: http://www.ufrgs.br/alcar/encontrosnacionais-1/encontros-nacionais/8o-encontro-2011-1/artigos/a\%20saga\%20 das\%20radios\%20comunitarias.pdf/view. Acesso em: 6 jan. 2020.

FELIX, Carla Baiense. Entre discursos: mídia e subjetividade nos espaços populares. Dissertação (Mestrado em Comunicação e Cultura) - Escola de Comunicação Social, Universidade Federal do Rio de Janeiro (UFRJ). Rio de Janeiro, 2008. Disponível em: http://www.pos.eco.ufrj.br/site/download.php?arquivo=upload/ disserta_cfelix_2008.zip. Acesso em: 6 jan. 2020.

FREIRE, Paulo. Comunicação e Extensão. Tradução de Rosiska Darcy de Oliveira. 1. ed. Rio de Janeiro: Paz e Terra, 2013.

G.R.E.S. ESTAÇÃO PRIMEIRA DE MANGUEIRA. Samba-enredo 2019. História Pra Ninar Gente Grande. Disponível em: http://www.mangueira.com.br/site/sambasenredo. Acesso em: 6 jan. 2020.

HALL, Stuart. A identidade cultural na pós-modernidade. Tradução de Tomaz Tadeu da silva e Guacira Lopes Louro. Rio de Janeiro: Lamparina, 2006.

HELLER, Agnes. 0 cotidiano e a história. Tradução de Carlos Nelson Coutinho e Leandro Konder. São Paulo: Paz e Terra, 2004.

KLÖCHKNER, Luciano; PRATA, Nair (Org.). História da Mídia Sonora: experiências, memórias e afetos de norte a sul do Brasil. Porto Alegre: EDIPUCRS, 2009. Disponível em:https://bibliodigital.unijui.edu.br:8443/xmlui/bitstream/handle/123456789/2853/ M\%c3\%addia\%20sonora.pdf?sequence=1\&isAllowed=y. Acesso em: 11 fev. 2020. KRENAK, Ailton. Ideias para adiar o fim do mundo. São Paulo: Companhia das Letras, 2019.

LINS, Consuelo; MESQUITA, Cláudia. Filmar o Real. Rio de Janeiro: Zahar, 2008. 
MALERBA, João Paulo. Rádios comunitárias no limite: crise na política e disputa pelo comum na era da convergência midiática. Tese (Doutorado em Comunicação e Cultura) - Escola de Comunicação, Universidade Federal do Rio de Janeiro (UFRJ). Rio de Janeiro, 2016.

MANNHEIM, Karl. El problema de las generaciones. Tradução Ignacio Sánchez de la Yncera. Revista Española de Investigaciones Sociológicas, Madrid, Centro de Investigaciones Sociológicas, n. 62, p. 193-242, 1993. Disponível em: http://www.reis. cis.es/REIS/PDF/REIS_062_12.PDF. Acesso em: 9 ago. 2020.

MARTÍN-BARBERO, Jesús. Dos meios às mediações: comunicação, cultura e hegemonia. Rio de Janeiro: UFRJ, 2001.

NOVAES, Regina; VITAL, Christina. A juventude de hoje: (re)invenções da participação social. In: THOMPSON, Andrés (Org.). Associando-se à juventude para construir o futuro. São Paulo: Petrópolis, 2006. p.107-147. Disponível em: http://www.emdialogo. uff.br/sites/default/files/a_juventude_hoje.pdf. Acesso em: 19 set. 2019.

PAIVA, Raquel. 0 retorno da comunidade: os novos caminhos do social. Rio de Janeiro: Ed. Mauad X, 2007.

PEIXOTO, Rodrigo Correa; ARENZ, Karl; FIGUEIREDO, Kércia. O movimento indígena no baixo Tapajós: etnogênese, território, Estado e conflito. Novos Cadernos NAEA, v. 15, n. 2, p. 279-313, dez. 2012.

PERUZZO, Cicilia Maria Krohling. Revisitando os Conceitos de Comunicação Popular, Alternativa e Comunitária. In: Congresso Brasileiro de Ciências da Comunicação (Intercom), Brasília, 29 set. 2006. Disponível em: http://www.portcom.intercom.org. br/pdfs/116338396152295824641433175392174965949.pdf. Acesso em: 8 jun. 2020.

RIBEIRO, Djamila. O que é o lugar de fala? Belo Horizonte, MG: Letramento, 2019.

SANTORO, Luiz Fernando. Vídeo nos movimentos populares. In: SILVA, Carlos Eduardo Lins; FESTA, Regina (Org.). Comunicação popular e alternativa no Brasil. São Paulo: Paulinas, 1986. p. 164-170.

SILVA, Marcella Rodrigues Tovar da. Informação, conhecimento e atitude: como o estímulo à participação e ao convívio pacífico com o outro pode empoderar a juventude. Monografia (Graduação em Comunicação Social/Jornalismo) Faculdades Integradas Hélio Alonso. Rio de Janeiro, 2011.

SOARES, Ismar de Oliveira. Educomunicação: o conceito, o profissional, a aplicação. São Paulo: Paulinas, 2011.

SODRÉ, Muniz. Antropológica do espelho: uma teoria da comunicação linear e em rede. Petrópolis: Vozes, 2002. 
A Ciência do Comum: notas para o método comunicacional. Petrópolis:

Vozes, 2014.

VAZ FILHO, Florêncio Almeida. A emergência étnica de povos indígenas no baixo rio Tapajós, Amazônia. Tese (Doutorado em Antropologia) - Programa de Pósgraduação em Ciências Sociais da Universidade Federal da Bahia (UFBA). Salvador, 2010.

Introdução. In: VAZ FILHO, Florêncio Almeida (Coord.). Pajés,

benzedores, puxadores e parteiras: os imprescindíveis sacerdotes do povo na Amazônia. Santarém, PA: UFOPA, 2016. p. 13-50.

VÍDEO NAS ALDEIAS. Home. Disponível em: http://www.videonasaldeias.org. br/2009/index.php. Acesso em: 6 jan. 2020.

VOLPATO, Marcelo de Oliveira. Comunicação Comunitária: trajetórias e inovações. Revista UNINTER de Comunicação, Curitiba, Centro Universitário Internacional, v. 2, n. 3, p. 217-232, jul./dez. 2014. Disponível em: https:// www.revistasuninter.com/ revistacomunicacao/index.php/revista/article/view/555. Acesso em: 19 jul. 2020.

WELLER, Wivian. A atualidade do conceito de gerações de Karl Mannheim.

Revista Sociedade e Estado, Brasília, Universidade de Brasília, v. 25, n. 2, maio/ ago. 2010. Disponível em: https://periodicos.unb.br/index.php/sociedade/article/ view/5537/5028. Acesso em: 9 ago. 2020.

WERÁ, Kaká. Kaká Werá at TEDx VilaMadá. TEDx Talks, maio 2010. Disponível em: https://www.youtube.com/watch?v=UK3Go8grhc0. Acesso em: 16 out. 2019. 